\title{
INOVAÇÃO EM SUBSIDIÁRIAS DE EMPRESAS MULTINACIONAIS: A APLICAÇÃO DO PARADIGMA ECLÉTICO DE DUNNING EM PAÍSES EMERGENTES
}

\author{
Eva Stal \\ estal@uninove.br \\ Universidade Nove de Julho - SP/Brasil \\ Milton de Abreu Campanário \\ campanario@uninove.br \\ Universidade Nove de Julho - SP/Brasil
}

Recebido em 25/12/2008

Aprovado em 29/03/2010

Disponibilizado em 01/08/2011

Avaliado pelo sistema double blind review

Revista Eletrônica de Administração

Editor: Luís Felipe Nascimento

ISSN 1413-2311 (versão on-line)

Editada pela Escola de Administração da Universidade Federal do Rio Grande do Sul.

Periodicidade: Quadrimestral

Sistema requerido: Adobe Acrobat Reader.

\section{INTRODUÇÃO}

Um tema relevante e atual para o Brasil refere-se à atração de centros de inovação de empresas multinacionais (EMNs). Estes contribuem para a produção de bens e serviços de tecnologia mais avançada, fortalecendo o desenvolvimento local, as exportações e a capacitação tecnológica nacional. A relevância se justifica pelo alto percentual de $\mathrm{P} \& \mathrm{D}$ que tais empresas realizam no país - quase 50\% de toda a atividade brasileira (BOEHE, 2007).

A globalização das atividades de P\&D é uma realidade entre as empresas multinacionais. Publicações da UNCTAD (2005a e 2005b) e da OCDE (2006) mostram a dispersão das atividades de inovação nas subsidiárias das EMNs, havendo, porém, diferenças na alocação de tais atividades entre as filiais em países desenvolvidos e aquelas situadas em países emergentes, além de diferenças entre setores industriais.

Existem vários tipos de unidades de P\&D em subsidiárias de EMNs. Algumas adaptam produtos globais às condições locais, enquanto outras têm um papel destacado no desenvolvimento de novos produtos, seja para mercados locais e regionais, ou para o mercado 


\section{Eva Stal \& Milton de Abreu Campanário}

mundial. Os centros de maior importância estratégica na estrutura global das EMNs são os que realmente contribuem para a capacitação nacional, e para que isso ocorra são necessários fatores de atratividade que compensem os custos de P\&D.

O paradigma eclético da produção internacional é uma das teorias mais completas para explicar as razões que levam as empresas a se internacionalizar, promovendo investimentos diretos em outros países (DUNNING, 1980, 1988, 1998, 2001). Conhecido como paradigma OLI, devido às variáveis ownership, location e internalization (propriedade, localização e internalização), ele define se vale a pena uma empresa se instalar em determinado país para explorar uma vantagem competitiva própria, ou se é melhor repassar esse ativo a uma empresa local. Isto pode ser feito por meio de uma licença, ou através do mercado, mediante a exportação de produtos.

Este modelo foi intensamente estudado (e também criticado) por diversos autores, que tentaram demonstrar a maior importância de um fator sobre os outros. Para Dunning, as características de uma variável podem sobressair em determinadas condições, porém as três são necessárias para uma decisão da empresa. Em geral, a variável "localização" reflete o ambiente de um país, por suas características políticas, econômicas, culturais e de mercado tamanho, dinamismo, regulamentação, barreiras tarifárias. Os conceitos do Investment Development Path (trajetória de desenvolvimento dos investimentos) complementam o paradigma OLI, ao mostrar como os governos podem contribuir para que os países avancem nas cinco etapas da trajetória, passando de meros receptores de investimentos externos a efetivos investidores (DUNNING, 1981; DUNNING, NARULA, 1996).

Desde 1991, o Brasil conta com a Lei de Informática (lei 8.248/91, modificada pelas leis 10.176/01 e 11.077/04), em vigor até 2019. Os incentivos concedidos são generosos (inicialmente, isenção total do IPI e, após 2001, redução significativa), o que estimulou não apenas a produção de equipamentos de informática, microeletrônica e telecomunicações no país, como o desenvolvimento tecnológico do setor. A lei exigia das empresas beneficiárias a aplicação de um percentual mínimo de 5\% do faturamento (hoje, 3,5\%) em atividades de pesquisa e desenvolvimento, internamente à empresa ou em colaboração com universidades e institutos de pesquisa. Este mecanismo tem se mostrado duplamente benéfico, pois possibilitou a atração de grandes empresas multinacionais do setor de TIC (Tecnologia de Informação e Comunicação), ao mesmo tempo contribuindo para a capacitação de pesquisadores e engenheiros locais, contratados pelas empresas para seus centros de inovação. Vários autores estudaram o papel das subsidiárias brasileiras de EMNs do setor de TIC para o desenvolvimento tecnológico da corporação e do sistema de inovação local, e chegaram a 
Inovação em subsidiárias de empresas multinacionais: a aplicação do paradigma eclético de dunning em países emergentes

conclusões distintas, como será visto adiante. Este artigo tem o objetivo de mostrar como as políticas públicas constituem um componente importante da variável "localização", do paradigma eclético de Dunning, especialmente para os países emergentes, mediante a análise da Lei de Informática. Procurou-se evidenciar como ela foi preponderante para a atração de EMNs e seus centros de $\mathrm{P} \& \mathrm{D}$, e os resultados positivos quanto à disseminação de conhecimento e a capacitação tecnológica das subsidiárias e dos institutos de pesquisa do setor, públicos e privados.

Especificamente, estudamos um aspecto peculiar da lei - a exigência de investimentos em P\&D em instituições externas -, que resultou na criação de institutos de pesquisa independentes, sem fins lucrativos. Tais institutos desenvolvem tecnologia própria, além de soluções tecnológicas para diferentes clientes, além das empresas fundadoras, e podem ter acesso aos Fundos Setoriais e a outras fontes de financiamento públicas, podendo receber investimentos de outras empresas, também beneficiárias dos incentivos da Lei de Informática. Entender seus efeitos na capacitação tecnológica nacional, através da interação com a infraestrutura local (universidades e institutos de pesquisa públicos) é o nosso segundo objetivo.

O artigo está organizado em seis seções, incluindo esta introdução. Na próxima seção, apresentamos o referencial teórico que contempla os principais conceitos sobre o tema. No item 3, apresentamos os procedimentos metodológicos. Na sequência, apresentamos os resultados das entrevistas, a análise e discussão dos resultados, as conclusões e, ao final, as referências utilizadas.

\section{REFERENCIAL TEÓRICO}

\subsection{A inovação nas subsidiárias das empresas multinacionais}

Diversos trabalhos examinaram os fatores associados às diferenças no papel das subsidiárias de EMNs, e três perspectivas concorrentes são dominantes (BIRKINSHAW, HOOD, JONSSON, 1998): a primeira é a do determinismo ambiental, e defende que cada ambiente tem suas próprias características, sendo o papel da subsidiária função do ambiente local. Se o país for estrategicamente relevante ou houver grande dinamismo do mercado - consumidores, fornecedores e concorrentes - a subsidiária terá um papel importante.

A segunda perspectiva defende que o papel da subsidiária é atribuição da matriz, responsável pela estratégia global da empresa, que pode melhor definir os papéis de cada filial. A terceira perspectiva considera a escolha da subsidiária, em que esta compreende o 


\section{Eva Stal \& Milton de Abreu Campanário}

mercado local e suas capacidades, e está em melhor posição que a matriz para definir o seu papel. Nesta perspectiva, os recursos e capacidades específicos da subsidiária, as aspirações do gerente/diretor e a iniciativa e esforço dos funcionários determinam o seu papel.

Assim, para uma completa compreensão do papel das filiais, é necessário considerar as características da matriz, da subsidiária, da indústria local e do país. Os dois primeiros aspectos enquadram-se na variável propriedade, enquanto os dois últimos enquadram-se na variável localização do paradigma eclético (DUNNING, 1980, 1988).

Boehe e Zawislak (2004) analisaram os estímulos externos que influenciam a inovação nas subsidiárias de EMNs, chegando a três tipos - o ambiente operacional, que trata das relações entre a empresa e seus clientes, fornecedores, universidades e institutos de pesquisa; o ambiente institucional, que se refere às condições e incentivos oferecidos pelo país hospedeiro; e o ambiente corporativo, composto pela matriz e pelas subsidiárias, e que influencia o papel estratégico de cada filial e sua respectiva contribuição à inovação. Aqui também se encontram semelhanças com a categorização de Dunning, podendo-se incluir os dois primeiros tipos de ambiente em localização e o terceiro em propriedade.

Outra contribuição para o tema são os conceitos de centro de excelência e mandato global de produto. No primeiro caso, trata-se de unidades que possuem um conjunto de capacidades reconhecidas pela empresa como importante fonte de criação de valor, uma vez que podem ser aproveitadas e/ou transferidas para outras partes da corporação (FROST, BIRKINSHAW, ENSIGN, 2002). O segundo conceito é similar, onde uma subsidiária tem a responsabilidade de desenvolver, fabricar e colocar no mercado uma linha de produtos em escala global, dada sua competência específica naquela tecnologia (BIRKINSHAW, HOOD, JONSSON, 1998). Oliveira Jr. e Borini (2006) definem a relevância estratégica de uma subsidiária como a competência em criar inovações transferidas e usadas por outras subsidiárias e pela matriz, definição similar à de centros de excelência.

A parceria com universidades e institutos de pesquisa locais pode melhorar a capacidade tecnológica da subsidiária, tornando-a um centro de excelência, cujo conhecimento poderá ser explorado globalmente pelas outras subsidiárias, especialmente em países de mesmas características culturais, socioeconômicas e climáticas (BOEHE, 2007). A capacidade de um centro de pesquisa empresarial, seja na matriz ou em uma subsidiária, utilizar ou aumentar suas competências tecnológicas depende não apenas de seus recursos, mas da eficiência com que utiliza recursos complementares presentes no sistema nacional de inovação. 
Inovação em subsidiárias de empresas multinacionais: a aplicação do paradigma eclético de dunning em países emergentes

\subsection{O paradigma eclético da produção internacional - a importância de cada fator}

John Dunning escreveu mais de 30 artigos e livros sobre o Paradigma Eclético da Produção Internacional, atualizando-o, incorporando contribuições e se defendendo de críticas. A realidade mostra que este modelo continua forte e atual. Ele apresentou o conceito pela primeira vez em 1976, em um simpósio em Estocolmo. Todavia, as ideias básicas já se formavam desde os anos 50, quando escreveu sua tese de doutorado, sobre o investimento de empresas americanas na indústria inglesa (DUNNING, 2001). Havia estudos mostrando que a produtividade da indústria manufatureira americana era, em média, duas a cinco vezes maior do que a da indústria britânica. A questão que preocupava Dunning era se a diferença de produtividade era resultado dos recursos endógenos (e imóveis) da economia americana, ou se o fato se devia à maneira mais eficiente com que os gerentes das empresas americanas organizavam e utilizavam esses recursos. Neste caso, esta competência poderia ser transferida de um país para outro, e as subsidiárias americanas na Inglaterra deveriam ter um desempenho semelhante ao das matrizes, e bem melhor que suas concorrentes locais. Ele identificou este efeito como específico de propriedade (O - ownership).

Por outro lado, se as subsidiárias inglesas apresentassem um desempenho comparável ao das concorrentes locais, e muito abaixo dos resultados das matrizes, isto se deveria às características não transferíveis da economia americana, o que ele chamou de componente específico de localização (L - location). O resultado mostrou que as subsidiárias não eram tão produtivas quanto as matrizes, mas eram melhores que as empresas inglesas, demonstrando que parte das diferenças eram devidas ao componente $\mathbf{L}$ e parte ao componente $\mathbf{O}$.

No simpósio de 1976, ao explicar a atividade das empresas fora de suas fronteiras nacionais, Dunning estendeu as vantagens de $\mathbf{O}$ e $\mathbf{L}$, incluindo um novo conjunto de escolhas que as empresas poderiam fazer: gerar e/ou explorar suas vantagens específicas de propriedade internamente, ou vender essas vantagens ou os seus direitos através do mercado, para outras empresas. A isto ele se referiu como vantagens de internalização (I - internalization). E este se tornou o terceiro componente do paradigma eclético, para explicar o escopo e a geografia das atividades de agregação de valor realizadas pelas EMNs (DUNNING, 2001).

Dunning reconheceu a forte influência das ideias de Buckley e Casson (1976) e de Rugman (1981), autores da Teoria da Internalização, sobre o componente (I), mas não aceitou suas críticas. Estes argumentavam que as falhas de mercado em mercados internacionais de produtos intermediários eram suficientes para justificar a existência das empresas 


\section{Eva Stal \& Milton de Abreu Campanário}

multinacionais e, portanto, a teoria da internalização explicaria melhor o comportamento das EMNs (EDEN, 2003).

Apesar de as atividades próprias em mercados externos contribuírem para aumentar as vantagens de $\mathbf{O}$, Dunning acredita que a capacidade de uma empresa se beneficiar de atividades internacionais está relacionada aos ativos que ela possuía antes de promover a internalização. Ou seja, as vantagens de propriedade fornecem a capacidade para internalizar mercados, enquanto as vantagens de internalização têm a ver com a vontade de fazê-lo.

A variável propriedade refere-se às capacidades específicas da empresa, que lhe permitem um melhor posicionamento no mercado estrangeiro, em comparação aos produtores locais ou a outros produtores estrangeiros. É o acesso privilegiado a algum ativo, economias de escala, patentes, marcas, capacidades tecnológicas e gerenciais, diferenciação de produtos, e que devem compensar o custo de montar e manter uma operação no exterior.

Diversos aspectos são determinantes da variável localização - custos do trabalho, transporte, energia e materiais, produção e comunicação, intervenção governamental (barreiras tarifárias, incentivos fiscais), distância psíquica, abundância de recursos naturais, infraestrutura, instituições, tamanho e dinamismo do mercado, presença de concorrentes ou de clusters, estabilidade política e econômica, entre outros. Analisadas as vantagens desses dois fatores, a empresa consideraria a alternativa de internalizar os seus recursos, produzindo no exterior com sua própria estrutura (por meio de subsidiárias ou associadas), ou ceder o uso de sua vantagem de propriedade através de contratos ou licenças. Produzir no exterior é uma decisão influenciada pela natureza dos ativos intangíveis, entre os quais o conhecimento tácito, que a firma pode usar, mas não vender ou licenciar, e que estimulam o investimento na produção internacional.

A intervenção governamental pode encorajar as empresas estrangeiras a internalizar suas atividades em determinado país. Isto é particularmente verdadeiro quanto à legislação sobre a produção e o licenciamento de tecnologia, incluindo o sistema local de patentes, e onde existem políticas diferenciadas sobre impostos e câmbio (DUNNING, 1980, 1998). A existência de diferentes fatores de localização levou as empresas a concentrar determinados tipos de atividades agregadoras de valor em um número limitado de locais. O que prevalece são os motivos para o investimento no exterior - a busca por recursos naturais, por mercados, por eficiência ou por ativos estratégicos que possam se somar às vantagens competitivas (O) (DUNNING, 1994; KUEMMERLE, 1997). Neste último caso, a dispersão de atividades inovadoras ainda ocorre preferencialmente entre os países desenvolvidos. E é esta a razão 
Inovação em subsidiárias de empresas multinacionais: a aplicação do paradigma eclético de dunning em países emergentes

principal para que os países emergentes disputem a instalação de subsidiárias e ofereçam componentes de localização que possam atrair tais atividades.

A maior parte dos estudos de Dunning se concentrou nos países desenvolvidos, onde o papel do governo na variável localização é menos necessário do que nos países emergentes. Nestes, deve haver um esforço concentrado de políticas públicas para atrair investimentos estrangeiros, especialmente em atividades de inovação e capacitação tecnológica.

Complementando o paradigma OLI, Dunning também contribuiu para a teoria de negócios internacionais com os conceitos do Investment Development Path (IDP), que relaciona a tendência de um país se internacionalizar com o seu nível de desenvolvimento econômico, e explica as várias fases que o país atravessa, ao passar de receptor de investimentos externos para o papel de investidor externo (DUNNING, 1981; DUNNING, NARULA, 1996). De acordo com o IDP, existe uma relação sistemática entre a estrutura, a magnitude e a natureza das atividades associadas ao investimento direto estrangeiro (IDE), e o nível de desenvolvimento econômico de um dado país. Países de baixo desenvolvimento econômico tendem a receber pouco investimento estrangeiro, como resultado de fracas vantagens específicas de localização. À medida que o país se desenvolve, suas vantagens de localização aumentam, atraindo mais IDE, o que, por sua vez, contribui para a acumulação de vantagens específicas de propriedade das empresas domésticas.

\subsection{A variável localização e políticas públicas nos países em desenvolvimento}

Ao localizar suas sucursais e instalações de pesquisa por todo o mundo, as empresas multinacionais contribuem para o desenvolvimento da capacidade inovadora dos países onde atuam (DUNNING, 1994), apesar de a atividade de P\&D executada por elas fora de seus países de origem representar um pequeno percentual do que realizam internamente.

O estabelecimento de fábricas em certos países, apenas em razão de baixos salários ou impostos, já não se justifica. As tarifas estão se reduzindo devido a acordos comerciais (União Europeia, Mercosul, NAFTA). E a crescente sofisticação no desenvolvimento e fabricação de produtos leva à necessidade de fornecedores de classe mundial, o que influi na escolha dos países onde se instalar e reduz a importância de baixos custos de matéria-prima, capital ou salários, levando-se em conta a diferença de produtividade dos trabalhadores. Mesmo na Índia e China, fábricas são construídas em Bangalore e Shangai, onde o preço da terra e os salários são maiores, mas há trabalhadores e fornecedores qualificados (FERDOWS, 1997).

Kumar (2001) afirma que os recursos que o país anfitrião oferece influenciam o nível de P\&D feito pelas empresas estrangeiras. A existência de um grande mercado doméstico, abundância 


\section{Eva Stal \& Milton de Abreu Campanário}

de pessoal de $\mathrm{P} \& \mathrm{D}$ de baixo custo, infraestrutura tecnológica (universidades e institutos de pesquisa) e de comunicações, proteção da propriedade intelectual, políticas de comércio, requisitos de desempenho no país e escala do esforço tecnológico nacional definem o tipo e o escopo da P\&D que será realizada pelas EMNs num dado país.

Vários trabalhos listam ações e instrumentos utilizados em diferentes países para atrair centros de P\&D (DODGSON, 2000; STAL, CAMPANÁRIO 2007, ZANATTA et al., 2007). Alguns são específicos para certos setores, como é o caso da Lei de Informática no Brasil.

O traço comum entre os países asiáticos é a adoção de políticas tecnológicas para a qualificação de mão-de-obra, educação técnica e superior, suporte à pesquisa básica, financiamento e incentivos a P\&D. Elas são combinadas a políticas de investimento seletivas, com o objetivo de aumentar o conteúdo tecnológico das atividades realizadas pelas filiais das EMNs e o grau de complementaridade com instituições locais (HIRATUKA, 2005).

Coréia, Taiwan, Cingapura, Malásia, Tailândia e Indonésia fizeram um esforço planejado para criar capital humano e capacidade de inovação local, visando à exportação de seus produtos. Taiwan enfatizou a educação em todos os níveis, concedeu incentivos fiscais e financeiros para indústrias estratégicas, como eletrônicos e TIC, além de incentivos especiais para firmas estabelecidas em parques tecnológicos. Cingapura priorizou a formação e capacitação de engenheiros e cientistas. Incentivos fiscais de até $200 \%$ das despesas com P\&D e financiamento com juros subsidiados foram concedidos às EMNs que treinassem trabalhadores locais nas matrizes, para depois transferir novas linhas de produtos para o país.

A China implantou, a partir de 1979, uma política de abertura aos investimentos estrangeiros, com a criação de zonas livres e joint-ventures. Estabeleceu acordos bilaterais com vários países para obter know-how e treinamento tecnológico. Um ato significativo foi a Decisão sobre a Reforma do Sistema de Gestão de Ciência e Tecnologia, em 1985, que foi o marco inicial da criação de Zonas de Desenvolvimento da Economia e da Tecnologia, Zonas de Desenvolvimento de Alta Tecnologia e Zonas de Livre Comércio. O país exigiu das empresas multinacionais a instalação de centros de P\&D locais, e abriu as portas ao IDE como forma de atrair tecnologia e aumentar a oferta de produtos mais sofisticados e de maior qualidade. O setor de telecomunicações foi um dos que mais recebeu investimentos totais e em P\&D (ZANATTA, QUEIROZ, 2007).

Assim, desde a metade da década de 90, a China tornou-se o maior receptor de investimentos diretos estrangeiros no mundo, e o mais importante entre os países em desenvolvimento, devido ao gigantesco mercado e ao baixo custo da mão-de-obra, além da disponibilidade de 
Inovação em subsidiárias de empresas multinacionais: a aplicação do paradigma eclético de dunning em países emergentes

cientistas e engenheiros altamente qualificados, universidades e institutos de pesquisa, agências governamentais pró-ativas e leis trabalhistas mais flexíveis.

Já a Índia iniciou um processo de reestruturação dez anos depois da China, ao reduzir consideravelmente as restrições ao investimento estrangeiro, principalmente no setor de eletrônica, reconhecendo a sua importância para a produtividade da indústria e dos serviços. O país teve um crescimento significativo no desenvolvimento de software, e grandes empresas, como Motorola, Texas Instruments, Quark, Veritas e Cisco, possuem centros de P\&D locais, devido ao volume e à alta qualidade técnica da mão-de-obra que domina a língua inglesa. À medida que adquiriam confiança na qualidade dos trabalhadores, expandiram suas operações e desenvolveram significativamente seu nível tecnológico, o que levou a um rápido crescimento da demanda por trabalhadores qualificados. Isso, por sua vez, colaborou para a expansão da infraestrutura na educação. A infraestrutura de telecomunicações e a qualidade dos profissionais são enfatizadas pelas EMNs (PATIBANDLA; PETERSEN, 2002; ZANATTA, QUEIROZ, 2007).

\subsection{A experiência brasileira da Lei de Informática}

A Lei de Informática brasileira foi lançada em 1991, passou por aprimoramentos e está em vigor até 2019 (Lei 11.077/04). Ela estimulou a produção de equipamentos de informática, microeletrônica e telecomunicações no país, inicialmente com isenção e, paulatinamente, redução de IPI - a partir de 2006, 70\% de redução. E contribuiu para o desenvolvimento tecnológico do setor, ao exigir a aplicação de um mínimo de 5\% (3,5\% a partir de 2006) em atividades de $P \& D$, internamente ou em colaboração com universidades e institutos de pesquisa. Com isso, o governo mostrou sua preocupação com aspectos importantes e complementares - a atração de empresas produtoras de bens e serviços e a obrigatoriedade do investimento em $\mathrm{P} \& \mathrm{D}$, fundamental para a qualificação de profissionais.

A lei foi essencial para a atração de grandes empresas internacionais do complexo eletrônico, tanto de equipamentos para telecomunicações (Lucent, Motorola, Nokia, Siemens, NEC, Ericsson), como de informática (Compaq, Texas Instruments). Foi responsável, também, pelo estabelecimento de uma rede de fornecedores, especialmente de empresas de manufatura, como Celestica, Solectron, Flextronics (GARCIA e ROSELINO, 2004). A exigência da aplicação de uma parte dos recursos de P\&D em instituições externas, situação peculiar da lei brasileira, resultou na criação de institutos de pesquisa por grandes empresas, nacionais e estrangeiras. Tais institutos têm um papel fundamental, tanto na complementação dos esforços de inovação das subsidiárias que os criaram, como na interação com a infraestrutura pública 


\section{Eva Stal \& Milton de Abreu Campanário}

de $\mathrm{P} \& \mathrm{D}$, contribuindo para a aprendizagem e a capacitação tecnológica local, como será descrito na seção 4 - Apresentação de Resultados.

As EMNs ainda concentram parte de suas parcerias com os institutos de pesquisa criados por elas. Na visão de Diegues e Roselino (2006), as interações com os demais agentes locais e a difusão do conhecimento tácito para outros agentes do pólo são inibidas. Porém Figueiredo (2006) estudou 18 institutos de pesquisa brasileiros do setor de Tecnologia da Informação e Comunicação (TIC), públicos, privados, independentes, ligados a universidades ou a empresas, e confirmou o avanço da capacitação tecnológica brasileira, com o estabelecimento de processos de aprendizagem intra-organizacionais e de ligações variadas com componentes da infraestrutura tecnológica e empresas, tanto no âmbito nacional como internacional.

Com a aplicação da lei 8.248, entre 1993 e 1999, cerca de 100 novas empresas aqui se instalaram, na maioria grandes firmas internacionais, que hoje produzem bens de informática em várias regiões. Foram gerados 30 mil empregos, e os investimentos em P\&D foram de $\mathrm{R} \$ 2,6$ bilhões. O saldo entre impostos federais pagos e a renúncia fiscal foi de $\mathrm{R} \$ 3,2$ bilhões, e 299 empresas receberam incentivos (SEPIN, 2000).

O relatório de 2009 da Secretaria de Política de Informática (SEPIN) mostra que o número de empresas incentivadas foi de 436, sendo 187 situadas em São Paulo. Os dados apontam para uma grande concentração das empresas industriais no estado, tanto em valor (59,5\%) como em número $(42,9 \%)$. Em vista do faturamento sobre os produtos incentivados, 10 empresas têm obrigação de aplicar em P\&D mais de R 10 milhões. Dessas, oito se localizam em São Paulo. A DELL aparece como localizada no Rio Grande do Sul, apesar de ter transferido, em 2007, a produção de desktops e notebooks para Hortolândia, região de Campinas. A planta gaúcha ainda mantém operações de call center e do centro de desenvolvimento de software.

As principais categorias de aplicação em P\&D são: equipamento (hardware), hardware com software embarcado, software (aplicativo) e software embarcado.

Foram realizados convênios com 88 organizações de pesquisa, 23 delas localizadas em São Paulo, o que mostra que as empresas estão aplicando os recursos em P\&D em instituições localizadas nas regiões Norte, Nordeste e Centro-Oeste, onde os incentivos fiscais são maiores. Em 2007, universidades e institutos de pesquisa de São Paulo concentravam metade das aplicações externas em P\&D.

Os Relatórios Demonstrativos apontam para um montante de investimentos em P\&D superior ao valor mínimo exigível pela Lei de Informática, em torno de 40\%, entre 2006 e 2009. Em 2009, os valores aplicados foram de $\mathrm{R} \$ 779.881 .807$, para $\mathrm{R} \$ 579.070 .429$ de obrigações, o 
Inovação em subsidiárias de empresas multinacionais: a aplicação do paradigma eclético de dunning em países emergentes

que configura um resultado positivo para a estratégia de exigência de investimento em $P \& D$ em troca dos benefícios da lei.

A tabela abaixo mostra alguns resultados agregados.

Tabela 1: Empresas beneficiárias da Lei de Informática em 2009

\begin{tabular}{|l|r|}
\hline Quantidade de empresas & 436 \\
\hline Faturamento total em produtos incentivados (R\$) & 23.656 .086 .341 \\
\hline Valor total dos incentivos fiscais & 3.074 .245 .778 \\
\hline Valor total dos impostos pagos s/ a venda de produtos incentivados & 4.477 .497 .613 \\
\hline Valor total dos compromissos de investimento em P\&D & 579.070 .429 \\
\hline Valor dos compromissos, aplicações próprias & 291.966 .955 \\
\hline Valor mínimo dos compromissos, aplicações conveniadas & 287.103 .473 \\
\hline Quantidade total de pessoal das empresas & 96.814 \\
\hline Quantidade total de pessoal das empresas, de nível superior & 22.843 \\
\hline Quantidade total de pessoal em atividades de P\&D & 6.746 \\
\hline Quantidade total de patentes requeridas pelas empresas & 335 \\
\hline
\end{tabular}

Fonte: Ministério da Ciência e Tecnologia (2010)

\subsection{O polo de alta tecnologia de Campinas}

O pólo de alta tecnologia de Campinas já foi objeto de vários estudos (GARCIA, 2001; CASSIOLATO, SZAPIRO, LASTRES, 2002; GOMES, 2003; DIEGUES, ROSELINO, 2006). Eles mostram as transformações que o pólo sofreu desde a sua constituição, nos anos 70, basicamente em torno do CPqD/Telebrás e da UNICAMP, passando pela privatização da Telebrás, em 1998, e as mudanças decorrentes da Lei de Informática, criada em 1991, e que atraiu para o local um grande número de empresas multinacionais.

Na região havia ainda a PUCCAMP - Pontifícia Universidade Católica de Campinas, e institutos de pesquisa como CTI - Centro de Tecnologia de Informática (atual CENPRA) e LNLS - Laboratório Nacional de Luz Sincrotron. A presença do CPqD e suas relações com as universidades e com empresas do setor estimulou um processo local importante de geração de inovações. Diversas empresas de pequeno e médio porte do setor de informática, especialmente produtoras de software, ali se instalaram. Algumas empresas pioneiras, como a IBM, lá estabelecidas há muitos anos, se preocuparam com a formação e capacitação de seus profissionais e de um conjunto de empresas locais fornecedoras de peças, componentes e serviços, o que gerou um processo de aprendizado entre os agentes locais (GARCIA, 2001).

Durante a década de 1980, CPqD e UNICAMP foram responsáveis por spin-offs, que resultaram na criação de novas empresas. Havia também uma alta taxa de rotatividade dos funcionários nas empresas e instituições de ensino e pesquisa, o que colaborou para a difusão de conhecimento tácito no polo. Nos anos de 1990, com a liberalização da economia, muitas firmas multinacionais lá se estabeleceram, adotando a estratégia de trazer seus fornecedores 


\section{Eva Stal \& Milton de Abreu Campanário}

globais, o que reduziu a participação dos produtores locais, antes protegidos pela reserva de mercado, que talvez não pudessem oferecer os mesmos preços e padrões de qualidade.

A privatização da Telebrás, em 1998, reflete o que ocorreu em quase todos os países - a privatização de empresas de telefonia e a introdução da concorrência nos serviços de telecomunicações. Com essas mudanças mundiais, os grandes fornecedores de equipamentos passaram a realizar $\mathrm{P} \& \mathrm{D}$, enquanto as operadoras se concentraram na prestação de serviços de telecomunicações (GRACIOSA et al., 2002; GALINA, SBRAGIA, 2004). Porém as atividades tecnológicas do polo foram preservadas. As EMNs destacam o papel decisivo da Lei de Informática, atraindo para as subsidiárias locais atividades de maior valor agregado, como o desenvolvimento de produtos, na concorrência com filiais em outros países. A região continuou a mobilizar grande número de profissionais em atividades tecnológicas, nas empresas e nas demais instituições (DIEGUES e ROSELINO, 2006).

Além da infraestrutura científico-tecnológica, pessoal altamente qualificado e proximidade do mercado consumidor, o pólo de Campinas possuía outros fatores de atratividade, como um excelente sistema viário e o aeroporto de Viracopos, que recebe a maior parte das cargas internacionais. Todavia, alguns dos trabalhos citados mencionam a "destruição do aparato institucional representado pelo sistema Telebrás, que fez com que capacitações acumuladas fossem quase totalmente perdidas" e "o profundo desarranjo, desaparecimento de empresas, eliminação de elos de cooperação entre instituições e sérias dúvidas quanto à continuidade do desenvolvimento tecnológico da região" (GARCIA, 2001). Galina e Sbragia (2004) comentam que "algumas aquisições de empresas locais resultaram na extinção ou subutilização da P\&D local, porém outras transformaram as subsidiárias em líderes mundiais em tecnologias dominadas pelas empresas adquiridas".

Uma breve análise do que ocorre atualmente na região mostra que ela continua uma das mais dinâmicas do país, especialmente nos setores de Informática e Telecomunicações. Campinas é pólo de uma região metropolitana formada por 19 cidades, entre as quais Hortolândia (sede de IBM e Dell), Indaiatuba (Ericsson) e Jaguariúna (Motorola). Há dois Parques de Alta Tecnologia, estabelecidos em áreas sujeitas a legislação municipal especial, e leis específicas de incentivos fiscais (Lei 12.653 de 10/10/2006), que estimulam a instalação de empresas de base tecnológica e têm por finalidade resguardar o meio ambiente, garantindo que somente empresas de alta tecnologia e não poluentes lá se alojem.

A CIATEC (Companhia de Desenvolvimento do Polo de Alta Tecnologia de Campinas) foi constituída por decreto municipal em 1991. Da mesma forma, foi transformada em empresa municipal de economia mista, mantendo a Prefeitura Municipal de Campinas como acionista 
Inovação em subsidiárias de empresas multinacionais: a aplicação do paradigma eclético de dunning em países emergentes

majoritária. Ela tem ativa participação no planejamento e execução da política de ciência e tecnologia da cidade, abriga o programa de incubadora de empresas de base tecnológica e coordena a implantação de empresas e organizações de pesquisa nos dois Polos.

O Polo II, onde já funciona o Laboratório Nacional de Luz Sincrotron (LNLS), ganhou em março de 2008 um novo laboratório de nanotecnologia. Também instalarão unidades no pólo a Natura, o Centro de Pesquisas e Desenvolvimento da Tecnologia da Informação (CPDTI) do Exército, o Instituto Eldorado e o Centro Nacional de Pesquisas da Biomassa.

Existe ainda a Fundação Fórum Campinas (FFC), instituída em 2002, e que envolve onze instituições de pesquisa e ensino localizadas na região metropolitana de Campinas, e tem por objetivo discutir propostas de atuação conjunta. Campinas é um dos 50 principais pólos de atração de investimentos no mundo. A região responde por 9\% do PIB nacional e atrai $16 \%$ dos investimentos correntes no Estado de São Paulo, superada apenas pela Grande São Paulo.

\subsection{A atratividade do Brasil para atividades de inovação tecnológica}

Estudo realizado pela SOBEET (Sociedade Brasileira de Estudos de Empresas Transnacionais e da Globalização Econômica) em 2000 revelou que, entre os fatores determinantes da decisão de investir em P\&D no Brasil, destacam-se a redução dos custos de produção, seguido da melhoria da qualidade do produto e da busca por novos mercados. A pesquisa mostrou ainda que, entre dez condicionantes que afetam a decisão de investir em inovação, as empresas apontaram nos quatro primeiros lugares a qualidade e a disponibilidade de mão-deobra especializada, e a mão de obra de nível superior. Os incentivos fiscais para P\&D apareceram apenas em nono lugar, seguidos por fontes de financiamento apropriadas. Isto porque esses são estímulos à inovação somente no caso de a estratégia da matriz ser a de descentralizar sua atividade inovadora, caso em que os fatores determinantes, citados anteriormente, prevalecem.

O World Investment Report 2005, da UNCTAD, mostrava o Brasil como um dos quinze maiores receptores de Investimento Direto Estrangeiro (IDE) no mundo. Considerando apenas os países em desenvolvimento, ele estava entre os cinco principais. Estes são os resultados de uma pesquisa feita com analistas, empresas transnacionais e agências de promoção de investimento sobre suas expectativas em relação ao desempenho dos fluxos de IDE no curto prazo (2005-2006).

Entretanto, quando o assunto foram as atividades de inovação, chama a atenção a má colocação do Brasil, especialmente entre os países em desenvolvimento. Para 68 empresas que responderam sobre as decisões futuras de alocação das atividades de P\&D, o Brasil foi 
Eva Stal \& Milton de Abreu Campanário

citado por apenas uma empresa (1,5\% da amostra). A baixa atratividade é mais intrigante pelo fato de $13,2 \%$ das empresas entrevistadas já investirem em P\&D no país, como mostra a tabela seguinte.

Tabela 2. Atratividade dos países para realização de P\&D (respostas de 68 EMNs)

\begin{tabular}{|c|c|c|c|}
\hline \multicolumn{2}{|c|}{ Localização de atividades de P\&D (2004) } & \multicolumn{2}{|c|}{$\begin{array}{l}\text { Alocação futura de atividades de P\&D } \\
(2005-2009)\end{array}$} \\
\hline País & $\begin{array}{l}\text { Freqüência das respostas } \\
(\%)\end{array}$ & País & $\begin{array}{l}\text { Frequiência das respostas } \\
(\%)\end{array}$ \\
\hline E. Unidos & 58,8 & China & 61,8 \\
\hline Reino Unido & 47,1 & E. Unidos & 41,2 \\
\hline China & 35,3 & Índia & 29,4 \\
\hline França & 35,3 & Japão & 14,7 \\
\hline Japão & 29,4 & Reino Unido & 13,2 \\
\hline Índia & 25,0 & Rússia & 10,3 \\
\hline Canadá & 19,1 & França & 8,8 \\
\hline Alemanha & 19,1 & Alemanha & 5,9 \\
\hline Cingapura & 17,6 & Holanda & 4,4 \\
\hline Itália & 14,7 & Canadá & 4,4 \\
\hline BRASIL & 13,2 & Cingapura & 4,4 \\
\hline Espanha & 13,2 & BRASIL & 1,5 \\
\hline
\end{tabular}

Fonte: SOBEET, com base em WIR/2005 - UNCTAD

Esses resultados mostram que, para as empresas entrevistadas, a variável Localização do Paradigma de Dunning tem um valor bastante reduzido no Brasil, levando-as a optar por outros países. Por outro lado, pesquisa realizada pela Economist Intelligence Unit em 2004 (ZANATTA e QUEIROZ, 2007), revela que o Brasil aparecia em sexto lugar, num ranking de 54 países, como alternativa para receber investimentos empresariais em $\mathrm{P} \& \mathrm{D}$, nos três anos seguintes. Essa discrepância de resultados demonstra, no mínimo, desconhecimento por parte dos países sobre as reais condições brasileiras para a realização de atividades de inovação.

Ainda segundo o WIR 2005 (ZANATTA e QUEIROZ, 2007), a atração de centros de P\&D demanda políticas que priorizem, em conjunto, os seguintes aspectos - recursos humanos, que envolve a política educacional do país; institutos de pesquisa, que devem estar articulados com as demandas das empresas privadas; efetiva proteção dos direitos de propriedade intelectual; e instrumentos que equilibrem os interesses de consumidores e fornecedores.

Novo estudo da UNCTAD, de 2010, mostra que os cinco países preferidos para investimentos externos entre 2010-2012 são agora, pela ordem, a China, Índia, Brasil, EUA e Rússia, numa pesquisa efetuada junto a 236 multinacionais e 116 agências de promoção de investimentos. A crise econômica global acentuou uma tendência recente, de mudança no foco geográfico das multinacionais em direção de economias em desenvolvimento e em transição. Essas economias se saíram melhor da crise e lideram a recuperação econômica global, tendo papel 
Inovação em subsidiárias de empresas multinacionais: a aplicação do paradigma eclético de dunning em países emergentes

maior nas estratégias das multinacionais. Nove entre as 15 destinações prioritárias para IDE são países em desenvolvimento ou em transição (UNCTAD, 2010).

\section{PROCEDIMENTOS METODOLÓGICOS}

A pesquisa realizada teve cunho descritivo e explicativo, para a compreensão das características dos institutos e as motivações estratégicas das empresas para a sua criação como instituições independentes sem fins lucrativos. A abordagem da pesquisa foi qualitativa (GODOY, 1995), mas se utilizou a triangulação, com o confronto de informações de fontes diferentes para enriquecer o trabalho, assegurar a consistência dos dados e reduzir a possibilidade de uma análise tendenciosa. O método escolhido foi o estudo de caso múltiplo (YIN, 2005; MARTINS, 2006). A possibilidade de utilizar várias fontes de evidência é uma das particularidades e vantagens dos estudos de caso. Os procedimentos metodológicos incluíram pesquisa bibliográfica, pesquisa documental e entrevistas em quatro institutos privados de pesquisa independentes: Instituto Eldorado, criado pela Motorola em 1999; Venturus Centro de Inovação Tecnológica, criado pela Ericsson em 1995, como Instituto de Pesquisa e Desenvolvimento em Informática e Automação - INFORMAT, e SIDI - Samsung Instituto de Desenvolvimento em Informática, todos sediados em Campinas. Entrevistamos também as empresas fundadoras - Motorola, Ericsson e Samsung. O quarto instituto entrevistado foi o $\mathrm{CPqD}$. Foram realizadas entrevistas semiestruturadas, em profundidade, com os dirigentes das empresas e dos institutos, e com os responsáveis pela área de Relações Governamentais, que se relacionam com o MCT para assuntos ligados aos incentivos da Lei de Informática. Os dados coletados, tanto nas entrevistas como nos documentos, foram analisados e interpretados mediante a técnica de análise de conteúdo (BARDIN, 2004; MARTINS, 2006). Esta técnica identifica tópicos comuns relacionados à estratégia de globalização das atividades de inovação, a distribuição dessas atividades pelos vários centros de $\mathrm{P} \& \mathrm{D}$, a autonomia das subsidiárias na definição de suas atividades de $\mathrm{P} \& \mathrm{D}$, a qualificação de pessoal, as interações com universidades e outros institutos de pesquisa, etc. A análise de conteúdo é um instrumental metodológico, que se pode aplicar a discursos diversos e a todas as formas de comunicação (GODOY, 1995).

Entre as várias técnicas da análise de conteúdo, a análise categorial é a mais antiga, e a mais utilizada. Funciona pela divisão do texto ou discurso em unidades ou categorias, por diferenciação e, em seguida, por reagrupamento, de acordo com critérios previamente definidos, num movimento contínuo da teoria para os dados e vice-versa, aonde as categorias vão se tornando cada vez mais claras. Entre as várias possibilidades de categorização, a 
Eva Stal \& Milton de Abreu Campanário

pesquisa dos temas, ou análise temática, é a mais eficaz na aplicação a discursos diretos, representados em nosso projeto pelas entrevistas.

\section{APRESENTAÇÃO DOS RESULTADOS}

\subsection{Motorola e Instituto de Pesquisas Eldorado}

A Motorola começou a produção no país atraída pelos benefícios da Lei de Informática, em 1996, e a ideia de realizar P\&D, além de cumprir com as exigências da lei, foi posterior à implantação da fábrica. Hoje, a unidade brasileira constitui a área de $\mathrm{P} \& \mathrm{D}$ da empresa na América Latina. O Centro de Pesquisa e Desenvolvimento de Terminais Celulares e Infraestrutura Celular abriga três centros de excelência mundiais nas áreas de Integração e Verificação de Software para telefonia celular (Brazil Test Center), Messaging (SMS), e Aplicações e Serviços de Infraestrutura. Desde 2005, todos os celulares produzidos pela Motorola têm passado pelo crivo da equipe brasileira antes de chegar ao mercado global.

A partir de sua instalação no país, a empresa apresentou trajetória ascendente de acumulação de capacidades tecnológicas, aproximando-se da fronteira tecnológica mundial em seu setor. O Brazil Semiconductor Technology Center participou de projetos globais na área de circuitos integrados, e se tornou uma empresa independente em 2004 (Freescale).

O Instituto Eldorado foi criado pela Motorola em dezembro de 1997, como uma associação sem fins lucrativos, para atender à exigência da Lei de Informática quanto a investimentos externos. Foi criado com foco em pesquisa e desenvolvimento na área de tecnologia da informação e comunicação e na capacitação de recursos humanos para este mercado Os profissionais - gerentes de projetos e engenheiros - foram selecionados no mercado, oriundos de diversas empresas do segmento privado, nenhum da Motorola (Ritz, 2008). Começou a funcionar de fato em 1999 e, em 2000, passou a ocupar instalações separadas da empresa, no Pólo de Alta Tecnologia de Campinas. Em 2009, passou a ocupar um terreno maior, contíguo à Unicamp, no Pólo II.

A Lei de Informática começou a vigorar em 1993, e durante esses anos a Motorola tentou fazer cooperação com universidades, mas havia muitas dificuldades - greves longas e freqüentes, tanto nas federais como na USP e Unicamp; dificuldade em aceitar fazer desenvolvimento, e não pesquisa básica; falta de compromisso com prazos e orçamentos; e a questão do sigilo e de direitos de propriedade intelectual, uma vez que os professores querem apresentar papers em congressos. Então a empresa decidiu formar competência própria em P\&D, criando o instituto. No início, eram apenas duas associadas: Motorola Industrial e 
Inovação em subsidiárias de empresas multinacionais: a aplicação do paradigma eclético de dunning em países emergentes

Motorola Serviços, e a atuação era a de uma entidade cativa. O estatuto foi reformulado, favorecendo a entrada de novas empresas. Hoje, o Eldorado conta com mais de 30 empresas como clientes, sendo mantido estritamente pelos projetos que executa. Também busca as universidades para novos projetos, com isso melhorando a sua capacitação. De 38 pessoas, passou a mais de 400 profissionais.

Em 2005 foi criado o Conselho Técnico-Científico, com 10 membros, vários da academia USP/São Carlos, Unicamp, CTA, Poli/USP, EBAPE/FGV, CGEE, FAPESP. O Conselho de Administração tem nove membros, de várias empresas, e a Motorola tem apenas um representante. $\mathrm{O}$ instituto atua nas seguintes áreas: a) gerenciamento de projetos, b) Projetos de P\&D: software, software embarcado, hardware, desenvolvimento de processos, testes e outros projetos; c) Programas de Capacitação; e d) Laboratórios.

O Eldorado faz alguns projetos para a matriz da Motorola, e assim como para qualquer outra empresa, sempre informa a subsidiária local. Não quer ser concorrente dela, ao contrário, quer ser valorizado para conseguir novos projetos. Há forte interação entre as equipes do Eldorado e das empresas contratantes.

A Motorola continua a manter uma área de P\&D interna e também tem forte parceria com o Instituto CESAR (Centro de Sistemas Avançados do Recife). A empresa não vinculou seus investimentos em P\&D à Lei de Informática, por isso a chance de eles continuarem é grande, mesmo com o fim dos incentivos, previsto para 2019. Mas, certamente, deverão diminuir.

\subsection{Ericsson e Venturus Centro de Inovação Tecnológica}

Desde os anos de 1970, a Ericsson desenvolve P\&D no Brasil, inicialmente na área de hardware e depois, a partir do início dos anos 80, em software. Começou com adaptações de produtos para o mercado brasileiro e, em 1980, desenvolveu a primeira central telefônica CPA no país (STAL, 2002). Em 1990, o centro brasileiro passou a projetar também produtos para o mercado mundial e a transferir tecnologia para outras subsidiárias.

A Ericsson possui 16 centros de pesquisa e 26 centros de desenvolvimento em vários países (Suécia, Alemanha, Estados Unidos, Itália, Finlândia, Canadá, Hungria, Noruega, Cingapura, Japão, China e Brasil). O centro brasileiro é considerado um centro de desenvolvimento. Em geral, não há centros de pesquisa em países emergentes, com exceção da China, por causa do potencial de mercado. Os temas mais estratégicos de pesquisa são tratados nos centros dos Estados Unidos, Canadá e Europa. A pesquisa no Brasil é $100 \%$ feita com universidades, de acordo com projetos de interesse global da matriz. A subsidiária faz a intermediação de 


\section{Eva Stal \& Milton de Abreu Campanário}

contratos de pesquisa entre universidades e institutos de pesquisa locais e a área de P\&D corporativa da Ericsson, contando para isso com apenas três pessoas.

Considerando a importância do mercado brasileiro e os incentivos da Lei de Informática, em 2001 a empresa expandiu suas atividades de P\&D no Brasil, quadruplicando o seu tamanho e criando o centro de Indaiatuba. Ele é o único centro da empresa na América Latina, onde hoje trabalham 110 engenheiros, além de possuir convênios de cooperação com várias universidades (UFRGS, PUC-RJ, USP e Unicamp) e institutos, como Venturus, Inatel (MG), Instituto Atlântico e CESAR, no Nordeste Cerca de 2500 produtos de software foram desenvolvidos entre 1995 e 2005. O centro brasileiro tem responsabilidade global pelo desenvolvimento de software da plataforma de comutação AXE e é também considerado um centro de excelência em billing systems (sistemas de tarifação). A empresa aplica mais recursos em P\&D do que o necessário para atender a lei porque existe competência local.

O Venturus foi criado pela Ericsson em 1995, como Instituto de Pesquisa e Desenvolvimento em Informática e Automação (INFORMAT), com estrutura autônoma, porém instalado no mesmo terreno do Centro de P\&D da empresa, em Indaiatuba. Em 2006, mudou de nome, transferiu suas instalações para Campinas e decidiu ampliar sua participação no mercado internacional. Atua no desenvolvimento e implantação de soluções tecnológicas, nas áreas de hardware e software para Telecomunicações e Automação.

A equipe que iniciou o projeto do instituto era formada por antigos funcionários da Engenharia da Ericsson. Hoje são mais de 300 funcionários. Além da Ericsson, são clientes/associados a Sony Ericsson (é o $6^{\circ}$ centro de competência da empresa no mundo, desenvolvendo softwares para celulares globais); a Toledo (desenvolvimento de sistemas e produtos para equipamentos de pesagem de cargas, animais e pessoas), a Emerson (sistemas e produtos de energia para indústria de telecomunicações), e a Tecpoint (equipamentos de automação bancária e comercial). Apesar de contar com muitos clientes, o instituto jamais atende uma empresa que seja concorrente direta das empresas fundadoras.

O Conselho Deliberativo do Venturus é formado por representantes das empresas fundadoras. Foi criado também o Conselho Técnico-Científico, do qual fazem parte entidades de ensino e centros de pesquisa em áreas afins, como CPqD, Centro Wernher Von Braun, CENPRA, UNICAMP, e a área de P\&D da Ericsson. A idéia, num futuro próximo, é tornar-se uma empresa privada de pesquisa, diversificando mais a base e os segmentos de clientes.

O Venturus foi reconhecido como um dos 10 melhores institutos de Pesquisa e Desenvolvimento em 2007, tendo recebido a Premiação Top Comm Award 2007. Os projetos que a Ericsson contrata ao Venturus estão relacionados às atividades que o grupo interno 
Inovação em subsidiárias de empresas multinacionais: a aplicação do paradigma eclético de dunning em países emergentes

realiza, funcionando como uma extensão daquele grupo. Em 2009, o instituto se tornou responsável pela validação dos softwares de automação comercial da Itautec. Em outubro daquele ano, o Venturus inaugurou novas instalações no Pólo II de Alta Tecnologia de Campinas.

\subsection{Samsung e SIDI - Samsung Instituto de Desenvolvimento em Informática}

A Samsung possui 5 divisões mundiais, totalmente independentes: Telecomunicações (aparelhos), Mídia (monitores, televisores, impressoras), Equipamentos do lar (geladeiras, micro-ondas, máquinas de lavar), LCDs (displays) e Semicondutores (LSI e HD). As áreas de P\&D também são independentes, reportando-se à divisão específica.

Em dezembro de 2006, a Samsung tinha 138 mil funcionários, sendo 86 mil na Coréia do Sul e 52 mil no exterior. O número total de pesquisadores era de 36 mil, ou $26 \%$ da força de trabalho. Desse total, 31 mil estavam na Coréia e 4.400 no exterior. As atividades de P\&D estão estruturadas em 3 camadas: equipes de desenvolvimento de produto, dentro de cada divisão, responsáveis por produtos que devem entrar no mercado dentro de um a dois anos; centros de $\mathrm{P} \& \mathrm{D}$ de cada negócio focalizam a tecnologia que deverá trazer resultados entre três e cinco anos. E o Corporate Technology Office, na matriz, desenvolve tecnologias fundamentais para novos negócios.

No Brasil a primeira fábrica foi instalada em Manaus, para o negócio Mídia. A Divisão de Celulares ocupou uma parte das instalações, depois veio para Campinas. O SIDI foi criado em 2004 para receber os recursos que a Samsung precisava alocar em pesquisa externa, para atender à Lei de Informática, e trabalha exclusivamente para a Divisão de Telecomunicações da empresa (celulares e soluções móveis). É o único dos institutos estudados em que as atividades não complementam as do grupo interno de P\&D da empresa. Mantém parcerias com várias universidades (UFPe, UFC) e institutos de pesquisa do Nordeste (CESAR, Instituto Atlântico), com o objetivo de criar capacitação local, dentro e fora da empresa. No início havia certa desconfiança da Samsung com relação ao centro brasileiro, mas casos de sucesso em projetos de alta complexidade, no desenvolvimento de software embarcado, salientaram a competência e a produtividade locais, especialmente na região de Campinas, que são equivalentes às da Coréia. São mais de 100 funcionários, com a conseqüente realocação de mais recursos por parte da matriz.

Como os demais institutos, o SIDI faz desenvolvimento, e a pesquisa é buscada na universidade. Um pequeno grupo interno de inovação mapeia as competências externas nas áreas de interesse da empresa. Na relação com universidades, surgem problemas com 


\section{Eva Stal \& Milton de Abreu Campanário}

propriedade intelectual, e demora em aprovar projetos. A empresa reformou e doou ao CESAR dois prédios, onde 150 pessoas trabalham em projetos de seu interesse.

O SIDI, como todos os centros de P\&D da Samsung, tem uma meta expressa em número de patentes, e já possui 12 pedidos registrados. Em 2006, a empresa registrou 17.377 patentes em todo o mundo, resultado do elevado investimento em P\&D (cerca de 10\% das vendas), que chegaram a cerca de US\$ 100 bilhões em 2007.

Atualmente, no Brasil, a empresa tem cerca de 500 pessoas trabalhando em P\&D, considerando as áreas de P\&D internas (desenvolvimento de produtos Telecom, equipamentos Wimax, 3G), o SIDI e os projetos em parceria com universidades e institutos de pesquisa.

Em 2008, a empresa ultrapassou os 5\% obrigatórios em P\&D que a lei exige, e existe a possibilidade de transferir para o SIDI a área interna de P\&D em telecomunicações. A empresa não se preocupa com o fim da lei de Informática em 2019, porque vale a pena manter um centro de P\&D no Brasil, onde há profissionais competentes, que entendem as necessidades da empresa e têm comunicação fluente com outras empresas e universidades.

\subsection{CPqD}

O Centro de Pesquisa e Desenvolvimento em Telecomunicações - CPqD - foi criado em 1976, como um instrumento de política setorial - a de capacitação tecnológica nacional no setor de telecomunicações -, cujo principal objetivo era o desenvolvimento de atividades que reduzissem a dependência do setor em relação à tecnologia estrangeira. Até 1998, foi um centro cativo do Sistema Telebrás.

A Telebrás havia sido criada em 1972, num modelo monopolista. Assim, foi possível a ela gerar receitas muito acima do necessário para cobrir os custos de operação. Cobrava tarifas mais baixas e executava programas de $\mathrm{P} \& \mathrm{D}$, com o objetivo de melhorar o desempenho das redes de telefonia. Como os recursos humanos eram escassos, a empresa contratou grupos universitários, no início.

Com a privatização da Telebrás, em julho de 1998, o CPqD tornou-se uma fundação privada sem fins lucrativos, multicliente. A partir de então, para garantir a sua sustentação, foram elaborados planos de trabalho combinados com as operadoras. A LGT (Lei Geral das Telecomunicações) garantiu a perenidade do $\mathrm{CPqD}$, mediante a criação de um fundo, que depois tornou-se o FUNTTEL, aprovado em agosto de 2000 (0,5\% de cada conta telefônica). No primeiro ano, $20 \%$ dos recursos eram destinados ao $\mathrm{CPqD}$, depois passou para $30 \%$, por decisão do conselho gestor do fundo. No início da era privada, isto representava $60 \%$ dos recursos do centro, hoje representa $25 \%$ da receita. Mas este dinheiro não entra 
Inovação em subsidiárias de empresas multinacionais: a aplicação do paradigma eclético de dunning em países emergentes

automaticamente na conta do $\mathrm{CPqD}$. Todo ano é preciso apresentar projetos para receber os recursos. Felizmente, há sempre mais ideias do que fundos. Hoje, o centro é uma organização independente (com 1.010 funcionários ao final de 2009) na geração de tecnologia e na comercialização de seu produto intelectual para clientes dos setores público e privado.

Até hoje, os projetos FUNTTEL envolveram a participação de 68 universidades e/ou institutos de pesquisa. Em outubro de 2003, foi criado o Fórum de P\&D, formado por sete representantes do meio acadêmico, para auxiliar na prospecção de linhas de P\&D com o propósito de contribuir para a inovação tecnológica adequada aos cenários atual e futuro da sociedade brasileira. Foi também aberta uma linha de pesquisa em TV digital.

O CPqD não é um instituto de pesquisa básica, desenvolve produtos para o mercado, e esta sempre foi a sua orientação, desde a criação. Só que no início o objetivo era o desenvolvimento de produtos nacionais, para diminuir a dependência tecnológica do país.

Hoje há diretorias puras de $\mathbf{P} \& \mathbf{D}$, para o desenvolvimento de idéias próprias, onde a tecnologia gerada é oferecida e transferida a um cliente externo através da Trópico, uma das organizações que compõem o Universo CPqD. Há também diretorias mistas de P\&D e produção, quando já existe contrato com um cliente.

Além desses, o centro tem ainda os seguintes produtos: sistemas de software, com propriedade intelectual, que ele vende e instala, e cujos concorrentes são EMNs; serviços tecnológicos, com mais de 700 ensaios credenciados pelo INMETRO; e empresas spin-offs, das quais o $\mathrm{CPqD}$ é acionista, por causa do capital intelectual. O instituto possui 109 patentes concedidas (1/3 registrada no exterior), 517 programas de software registrados e 126 processos de marcas (Relatório Anual 2009). O Universo CPqD é formado pelas seguintes instituições:

Instituto Atlântico, criado pelo CPqD em 2001, em Fortaleza, por causa dos incentivos fiscais maiores na região Nordeste. Ele não é uma filial, é uma associação civil sem fins lucrativos, tem outros associados (não controladores ou sócios), pois a lei de Informática exigia que a sede ou o negócio principal da organização estivesse nas regiões incentivadas. No início, para alavancar o instituto, 95\% dos recursos vinham de subcontratos com o CPqD. Hoje são apenas 5\%. Está se formando um pólo importante de tecnologia naquela região, o que tem atraído empresas e colocado novos desafios, especialmente a formação de doutores.

Secrel International- criada em 2007, é uma parceria com a empresa inglesa Firm Economics, o Instituto Atlântico e a empresa cearense Secrel, para produção terceirizada de softwares e serviços offshore. 
Eva Stal \& Milton de Abreu Campanário

Padtec (Produtos de Alto Desafio Tecnológico Ltda.) - empresa criada em 1999, fabrica dispositivos e equipamentos de comunicações óticas. Hoje tem 200 funcionários, é o maior produtor brasileiro, comprou a empresa israelense CIVCOM, abriu o capital e o CPqD possui 2/3. Disputa o mercado internacional com empresas chinesas, além da Siemens e Alcatel.

Trópico - pertence à Promon (60\%), Cisco (10\%) e CPqD (30\%). O CPqD havia desenvolvido a tecnologia Trópico de centrais telefônicas eletrônicas, na década de 1970. Por falta de recursos para novos desenvolvimentos, o centro decidiu entrar, em 1999, com a tecnologia na empresa Promon Tecnologia, que passou então a se chamar Trópico. A empresa produz equipamentos de nova geração, compete com EMNs, e está em crescimento acelerado.

CPqD Technologies \& Systems, Inc. - criada em 2000, em Fort Lauderdale, Flórida, para comercializar serviços, soluções de tecnologia de convergência. A ida para o exterior trouxe reconhecimento e novos clientes para a instituição no Brasil.

Clear Tech - criada em 2000. Antes da privatização só existia o sistema Telebrás, e os interurbanos eram repassados para a Embratel. O CPqD criou um software que faz o clearing de telecomunicações, separa os valores que cada operadora recebe de uma ligação que envolve distintas empresas de telefonia. Com este software, associou-se à EDS, multinacional americana e à DBA, empresa de software carioca, criando a ClearTech (1/3 de cada empresa). Há pouco a Clear Tech ganhou o contrato para administrar a portabilidade numérica (transferência de operadora de celular, mantendo o mesmo número).

Já! - é um minúsculo braço industrial do $\mathrm{CPqD}$, para a fabricação de protótipos.

Em agosto de 2008 foi criada uma Diretoria de Novos Negócios, dedicada a spin-offs, a partir de idéias de funcionários. Já houve geração espontânea, agora é importante a indução. A expectativa é que o Universo CPqD aumente com esta iniciativa.

As empresas Padtec, Trópico e Já investem recursos pela Lei de Informática e muitas vezes contratam outros institutos e universidades.

Em relação à governança, o instituto tem um Conselho Curador formado por 12 pessoas quatro do governo (FINEP e Ministério das Comunicações), duas de operadoras (presidentes da Vivo e Telefônica), duas da comunidade acadêmica, duas da sociedade civil e duas de clientes, incluindo o vice-presidente da Embraer, o presidente do Grupo Algar, e os presidentes da Icatel e da Trópico.

Em termos de resultados, pode-se afirmar que o volume de mercado brasileiro conquistado pelas tecnologias do CPqD, desde meados de 1998 (privatização) até 2009, corresponde a 12,7 bilhões de reais, com tecnologia gerada localmente. É preciso destacar que, segundo os entrevistados, tudo isso seria impossível se o $\mathrm{CPqD}$ ainda fosse um centro de pesquisa público. 
Inovação em subsidiárias de empresas multinacionais: a aplicação do paradigma eclético de dunning em países emergentes

\section{ANÁLISE E DISCUSSÃO DOS RESULTADOS}

Desde o início dos anos de 1980, o Paradigma Eclético constitui a principal explicação para o crescimento da atividade multinacional. Sua simplicidade e abrangência possibilitaram a utilização em diferentes setores e atividades, permitindo compatibilizá-lo com várias escolas de pensamento econômico e gerencial (CANTWELL; NARULA, 2001). Ele também recebeu críticas, e as novas formas organizacionais que surgiram no processo de globalização, como as alianças, trazem novos desafios para a sua aplicação, entre os quais se destaca a dispersão geográfica das atividades de inovação das EMNs, que passaram a alocar parte de sua P\&D em diversas subsidiárias, mais recentemente em países em desenvolvimento. Nestes países, as variáveis $\mathbf{O}, \mathbf{L}$ e $\mathbf{I}$ têm pesos distintos, e existem instrumentos que os governos podem mobilizar para fortalecer a variável $\mathbf{L}$.

Apresentado pela primeira vez em um congresso, em 1976, e depois publicado como artigo em 1980, o Paradigma Eclético considerava a expansão de empresas multinacionais apenas para outros países desenvolvidos. Assim, a variável L considera os custos do trabalho, de transporte, de energia e materiais, de produção e de comunicação, distância psíquica, abundância de recursos naturais, infraestrutura, instituições (leis e estruturas sociais de gestão pública), o tamanho e o dinamismo do mercado, a presença de concorrentes ou de clusters, e a estabilidade política e econômica. A intervenção governamental, mediante o uso de barreiras tarifárias e de incentivos fiscais, é considerada, mas se refere basicamente a barreiras protecionistas que os países adotam para proteger as suas empresas. A legislação sobre a produção e o licenciamento de tecnologia, incluindo um sistema local de patentes que proteja a propriedade intelectual, é também um aspecto importante da variável $\mathbf{L}$, mas muito relacionado aos países centrais, onde se realizavam as atividades de inovação, naquela época. Em artigo de 1994, Dunning abordou as razões para as EMNs se expandirem geograficamente, e classificou os países de acordo com essas motivações - busca de recursos, de mercados, de eficiência e de ativos estratégicos. As duas primeiras razões e, em alguns casos, a terceira, se aplicavam aos países em desenvolvimento. Mas a última motivação ocorria quando as EMNs instalavam subsidiárias em países desenvolvidos ou em países emergentes mais avançados.

Existe uma forte interdependência entre as vantagens de $\mathbf{O}$ e de $\mathbf{L}$. As EMNs possuem claras vantagens de propriedade (tecnologia, patentes, diferencial competitivo) e vão para determinado país devido às vantagens de localização, ao mesmo tempo em que contribuem para aumentar essas vantagens, despertando o interesse de outras EMNs por aquele país. 


\subsection{O polo tecnológico de Campinas e o paradigma OLI}

Artigos que descrevem o polo tecnológico de Campinas, escritos pouco depois da privatização da Telebrás (GARCIA, 2001; CASSIOLATO; SZAPIRO; LASTRES, 2002), exibem um sentimento de frustração com o desenrolar dos acontecimentos, que pode ser verificado por expressões como profundo desarranjo do polo; parte significativa dessas capacitações foi desperdiçada; destruição do aparato institucional; capacitações locais acumuladas foram quase totalmente perdidas. Já trabalhos publicados em anos seguintes (GOMES, 2003; GARCIA e ROSELINO, 2004; DIEGUES e ROSELINO, 2006) contêm uma avaliação mais favorável sobre os rumos que o polo tomou. Não apenas porque o passar do tempo enseja observações menos emocionais, mas devido ao fato de que o polo continua a atrair empresas do setor de TIC, bem como profissionais altamente qualificados. O CPqD é hoje uma fundação privada de grande sucesso na prestação de serviços de alto conteúdo tecnológico; e as interações entre empresas, universidades e institutos públicos se mantêm, em parte enriquecidas pelas parcerias com os institutos de pesquisa privados.

A criação desses institutos pelas EMNs foi propiciada por uma condição peculiar da Lei de Informática, que exigia o investimento de um percentual do faturamento das empresas em atividades de $P \& D$ realizadas externamente. Com esta exigência, o governo, na verdade, pretendia direcionar recursos das empresas para as universidades e institutos públicos, que viam o orçamento federal se reduzir a cada ano. As empresas perceberam uma dupla oportunidade: como organizações sem fins lucrativos, os institutos poderiam receber recursos da empresa fundadora, de outras empresas, do governo (fundos setoriais) e, ao mesmo tempo, promover a interação da empresa-mãe com as universidades. Esta interação não costuma ser tranquila, por conta de diferenças entre objetivos, prazos, sigilo de resultados, burocracia, exigências da universidade sobre direitos de propriedade intelectual, falta de interesse dos pesquisadores acadêmicos em realizar pesquisa aplicada e/ou desenvolvimento, entre outras.

Muitas empresas criaram, nos institutos, competências que não existiam. O MCT, que concede os incentivos, estimulou os institutos a se separarem fisicamente das empresas fundadoras, o que facilita a interação com outras firmas. Com o tempo, eles passaram a buscar novos clientes, a ponto de hoje terem que decidir se desenvolvem projetos para empresas concorrentes, mesmo com a proteção de contratos de confidencialidade.

Algumas referências aos institutos privados, na literatura, não são propriamente lisonjeiras. Sua criação é vista como resultado de uma brecha, falha ou deformação da lei de Informática, que permitiu a alocação de recursos que deveriam ser investidos em instituições de P\&D externas. Todavia, os resultados têm sido bastante positivos, pois os institutos 
Inovação em subsidiárias de empresas multinacionais: a aplicação do paradigma eclético de dunning em países emergentes

trabalham em sintonia com as empresas, que continuam a manter grupos internos de desenvolvimento; muitas vezes fazem a intermediação das empresas com as universidades; capacitam seus próprios profissionais, oferecendo bolsas de mestrado, doutorado e estágios no exterior; e, principalmente, fazem desenvolvimento de produtos, atividade fundamental no processo de inovação tecnológica. O que ocorreu foi o surgimento de um novo tipo de organização privada, rara no país, porém presente nos países desenvolvidos.

\subsection{A Lei de Informática e o Paradigma OLI}

A maioria das subsidiárias das EMNs está se concentrando nas atividades de concepção e design, desenvolvendo soluções para determinados produtos, dentro da corporação, e terceirizando a parte de produção, montagem, e algumas vezes, logística. Cada vez mais, o desenvolvimento de softwares ganha importância na inovação de produtos. Devido ao baixo custo dos investimentos em laboratórios de desenvolvimento de software, esta atividade tem grande mobilidade internacional (GOMES, 2003). Ou seja, o principal fator decisório é a disponibilidade de pessoal qualificado (variável L de Dunning), caso em que a Índia e o Brasil vêm se destacando entre os países emergentes.

Os incentivos fiscais foram fundamentais para justificar a implantação de centros de desenvolvimento no Brasil. Já a decisão de consolidá-los e expandi-los se deu em função do desempenho. Nas entrevistas, foram enfatizadas a alta qualidade, dedicação, flexibilidade, persistência e criatividade dos engenheiros brasileiros. Para muitas empresas aqui estabelecidas, a Lei de Informática foi responsável pela atribuição de novas responsabilidades à subsidiária brasileira dentro das redes tecnológicas globais. Outro fator não menos importante foi o contínuo desenvolvimento de competências ao longo dos anos por parte das subsidiárias como uma condição necessária para receber novas tarefas da matriz (GALINA e SBRAGIA, 2004). Várias empresas estão realizando no Brasil parte do esforço mundial de pesquisa e desenvolvimento.

As subsidiárias brasileiras têm posição privilegiada dentro da corporação, no que se refere a $\mathrm{P} \& \mathrm{D}$, por possuírem capacidade em determinada atividade, podendo, assim, ser consideradas como uma Subsidiária de Relevância Estratégica (OLIVEIRA JR. e BORINI, 2006) ou Centro de Excelência (BIRKINSHAW, HOOD, JONSSON, 1998; FROST, BIRKINSHAW, ENSIGN, 2002), e algumas têm mandato global para certos produtos. O papel e a relevância das subsidiárias das EMNs deste setor no Brasil devem ser atribuídos à complementaridade entre as atividades tecnológicas realizadas nos centro de P\&D das empresas e os desenvolvimentos que são terceirizados para os institutos privados. Neste caso, o 


\section{Eva Stal \& Milton de Abreu Campanário}

determinismo ambiental é fator preponderante. Mas o governo pode aperfeiçoar as variáveis locais, influenciando tanto a perspectiva da atribuição da matriz como a perspectiva da escolha da subsidiária.

Ao exigir das empresas investimentos em P\&D, a Lei de Informática contribuiu decisivamente para inserir as subsidiárias brasileiras das EMNs em redes de inovação globais, além de fomentar a constituição de redes locais com universidades e institutos de pesquisa. Esta exigência influenciou favoravelmente a variável $\mathbf{L}$, aumentando a atratividade do Brasil neste setor. De acordo com o Investment Development Path, o Brasil já é, há muito tempo, um país atraente para investimentos estrangeiros em produção, o que explica o seu posicionamento no segundo estágio, dentre os cinco definidos por Dunning (1981). Mas, quanto à realização de $\mathrm{P} \& \mathrm{D}$, a Lei de Informática foi decisiva para atrair a atenção das multinacionais estrangeiras. Como os recursos para P\&D já eram gastos previstos pelas empresas para o pagamento de impostos, ficou muito barato fazer atividades de desenvolvimento local. Com isso, elas puderam testar a qualidade dos grupos nacionais frente a outras subsidiárias, o que resultou na atração de projetos que seriam desenvolvidos em outros países.

O Brasil, por meio da Lei de Informática, fortaleceu a variável $\mathbf{L}$ para atrair as EMNs do setor. A própria vinda de algumas empresas atraiu o interesse de outras pelo país, o que ajudou a reforçar L. Mas a lei obriga as empresas a fazer P\&D e alianças com universidades e institutos de pesquisa. Com isso, a subsidiária fortalece a sua variável $\mathbf{O}$ e fica mais forte frente a subsidiárias em outros países, o que atrai novos projetos para cá e ela consegue atribuições mais importantes por parte da matriz. Assim, $\mathbf{L}$ reforça $\mathbf{O}$, ocasionando um efeito claro sobre a variável I - maior vantagem em internalizar a P\&D no Brasil.

Instrumentos específicos como incentivos físcais condicionados a desempenho podem influenciar o custo dos investimentos, levando ao aumento da inovação nas empresas. Vários autores enfatizam a superioridade desses incentivos quando comparados a incentivos de caráter geral (PERINI, 2007). A interação entre os centros de P\&D das subsidiárias de empresas multinacionais e as organizações locais (universidades, institutos de pesquisa, empresas de engenharia, clientes e fornecedores) é uma pré-condição para que ocorra a difusão do conhecimento (BOEHE, 2007). E é isto que se observa no pólo de Campinas. 
Inovação em subsidiárias de empresas multinacionais: a aplicação do paradigma eclético de dunning em países emergentes

\section{CONCLUSÕES}

Este artigo teve como objetivo mostrar que a variável localização (location) do Paradigma Eclético de Dunning, uma das mais abrangentes teorias que explicam o processo de internacionalização de empresas, pode ser reforçada por meio de políticas públicas ativas, especialmente no caso de países em desenvolvimento.

Ao se analisar o potencial do Brasil para P\&D no setor de TIC, verifica-se que ainda há carência de profissionais qualificados em certas áreas, o volume total de recursos humanos ainda é pequeno, e a legislação trabalhista constitui uma forte barreira.

Os institutos privados de pesquisa congregam um número significativo, porém ainda insuficiente, de profissionais extremamente capacitados - 300 no Venturus, 400 no Eldorado, 100 no SIDI, 100 no Genius, 1.000 no CPqD (cerca de 5.000 em todo o país) - e constituem um novo modelo de instituição dentro do Sistema Nacional de Inovação. Vários desses institutos, dada a competência adquirida e a diversidade de clientes e projetos de desenvolvimento, consideram a possibilidade de, num futuro próximo, se tornarem empresas privadas de pesquisa, com fins lucrativos. Muitos ex-funcionários do CpqD e do CENPRA estão hoje nos institutos privados e também nas subsidiárias das EMNs, o que configura a disseminação de conhecimento entre as diferentes organizações do pólo. A interação das empresas com as universidades está ocorrendo através dos institutos privados, que buscam o conhecimento na universidade e desenvolvem o produto para os clientes empresariais.

A continuidade das atividades de $\mathrm{P} \& \mathrm{D}$ das empresas não parece estar atrelada à existência dos incentivos, que terminam em 2019. Todos reconhecem a sua extrema importância como impulsionador dos esforços iniciais, principalmente pela oportunidade de demonstrar a qualidade das atividades realizadas no país. Mas o próprio desenvolvimento do setor já mostrou a sua eficácia, e os esforços de inovação por parte das empresas deverão continuar.

As empresas multinacionais influenciam o desenvolvimento e a difusão de inovações entre as fronteiras nacionais por meio de vários mecanismos, entre os quais o investimento direto estrangeiro, comércio, licenciamento, ações de patenteamento cruzado e colaborações internacionais em ciência e tecnologia. Todas essas modalidades envolvem uma grande variedade de agentes econômicos, mas as EMNs continuam a ocupar um papel central (NARULA; ZANFEI, 2005).

Os resultados deste trabalho podem contribuir para a sugestão de políticas públicas de inovação voltadas a outros setores, e também para a atualização dos conceitos do Paradigma Eclético de Dunning, em relação aos países emergentes. Dada a necessidade imperiosa de 
Eva Stal \& Milton de Abreu Campanário

aumentar as atividades de inovação no país, a atuação das empresas multinacionais torna-se de enorme relevância, e a combinação de instrumentos de política pública, exigências de capacitação local e um grande mercado podem indicar um caminho sustentável de desenvolvimento tecnológico e econômico para o Brasil.

\section{REFERÊNCIAS}

BARDIN, L. Análise de conteúdo. 3. ed. Lisboa: Edições 70, 2006.

BIRKINSHAW, J.; HOOD, N.; JONSSON, S. Building firm-specific advantages in multinational corporations: the role of subsidiary initiative. Strategic Management Journal, Hoboken, v. 19, n. 3, p. 221-241, Mar. 1998.

BOEHE, D. M. Os papéis de subsidiárias brasileiras na estratégia de inovação de empresas multinacionais brasileiras. Revista de Administração, São Paulo, v. 42, n. 1, p. 5-18, jan./fev./mar. 2007.

BOEHE, D. M.; ZAWISLAK, P. A. O ambiente e a inovação: desenvolvimento de produtos em subsidiárias de empresas multinacionais no Brasil. In: SIMPÓSIO DE GESTÃO DA INOVAÇÃO TECNOLÓGICA, 23., 2004, Curitiba. Anais.... São Paulo: PGT/USP, 2004. 1 CD-ROM.

BRASIL. Lei $\mathbf{n}^{\mathbf{1 1} .077}$, de 30.12.2004. Disponível em: <http://www.mct.gov.br/index.php/content/view/3282.html>. Acesso em: 27 set. 2008.

BUCKLEY, P. J.; CASSON, M. C. The future of the multinational enterprise. London, McMillan, 1976.

CANTWELL, J.; NARULA, R. The eclectic paradigm in the global economy. International Journal of the Economics of Business, Abingdon, v. 8, n. 2, p. 155-172, July 2001.

CASSIOLATO, J. E.; SZAPIRO, M. H. S.; LASTRES, H. M. M. Local system of innovation under strain: the impacts of structural change in the telecommunications cluster of Campinas, Brazil. International Journal of Technology Management, Olney, v. 24, n. 7/8, p. 680-704, 2002.

DIEGUES, A. C.; ROSELINO, J. E. Interação, aprendizado tecnológico e inovativo no polo de TIC da região de Campinas: uma caracterização com ênfase nas atividades tecnológicas desenvolvidas pelas empresas beneficiárias da Lei de Informática. Revista Brasileira de Inovação, Rio de Janeiro, v. 5, n. 2, p. 373-402, 2006.

DODGSON, M. Policies for science, technology and innovation in Asian newly industrializing economies. In: KIM, L.; NELSON, R. R. (Eds.). Technology, Learning \& Innovation. Cambridge: Cambridge University Press, 2000. p. 229-268.

DUNNING, J. Location and the multinational enterprise: a neglected factor? Journal of International Business Studies, Basingstoke, v. 29, n. 1, p. 45-59, 1998.

DUNNING, J. Multinational enterprises and the globalization of innovatory capacity. Research Policy, Amsterdam, v. 23, n. 1, p. 67-88, Jan. 1994.

DUNNING, J. The eclectic (OLI) paradigm of international production: past, present and future. International Journal of the Economics of Business, Abingdon, v. 8, n. 2, p. 173190, 2001. 
Inovação em subsidiárias de empresas multinacionais: a aplicação do paradigma eclético de dunning em países emergentes

DUNNING, J. The eclectic paradigm of international production: a restatement and some possible extensions. Journal of International Business Studies, Basingstoke, v. 19, n. 1, p 1$31,1988$.

DUNNING, J. Toward an eclectic theory of international production: some empirical tests. Journal of International Business Studies, Basingstoke, v. 11, n. 1, p. 9-31, 1980.

DUNNING, J.; NARULA, R. The Investment Development Path Revisited: Some Emerging Issues. In Dunning, John H. \& Rajneesh Narula (editors) Foreign Direct Investment and Government Catalysts for Economic Restructuring. London: Routledge, 1996.

EDEN, L. A critical reflection and some conclusions on OLI. In: CANTWELL, J.; NARULA, R. (editors.). International business and the eclectic paradigm: developing the OLI framework. New York: Routledge, 2003. p. 277-297.

FERDOWS, K. Making the most of foreign factories. Harvard Business Review, Boston, v. 75, n. 2, p.73-88, Mar./Apr. 1997.

FIGUEIREDO, P. N. Capacidade tecnológica e inovação em organizações de serviços intensivos em conhecimento: evidências de institutos de pesquisa em Tecnologias da Informação e da Comunicação (TICs) no Brasil. Revista Brasileira de Inovação, Rio de Janeiro, vol.5, n. 2, p. 403-454, 2006.

FROST, T. S.; BIRKINSHAW, J. M.; ENSIGN, P. C. Centers of excellence in multinational corporations. Strategic Management Journal, Hoboken, v. 23, n. 11, p. 997-1018, 2002.

Fundação CPqD. Relatório Anual. Campinas, 2009

GALINA, S. V. R.; SBRAGIA, R. Comportamento empresarial tecnológico: alguns indicadores no setor de telecomunicações. In: SBRAGIA, R.; GALINA, S. V. R. (Eds.). Gestão da inovação no setor de telecomunicações. São Paulo: PGT/USP, 2004. P. 87-117.

GARCIA, R. A importância da dimensão local da inovação e a formação de Clusters em setores de alta tecnologia. Revista Ensaios (FEE), Porto Alegre, v. 22, n. 1, p. 143-160, 2001.

GARCIA, R.; ROSELINO, J. E. Uma avaliação da lei de informática e de seus resultados como instrumento indutor de desenvolvimento tecnológico e industrial. Gestão \& Produção, São Carlos, v. 11, n. 2, p.177-185, mai./ago. 2004.

GODOY, A. S. Introdução à pesquisa qualitativa e suas possibilidades. Revista de Administração de Empresas, São Paulo, v. 35, n. 2, p. 57-63, mar./abr. 1995.

GOMES, R. O papel das subsidiárias e a internacionalização das atividades tecnológicas pelas empresas transnacionais (ETNs). Gestão \& Produção, São Carlos, v. 10, n. 3, p. 267-281, dez. 2003.

GRACIOSA, H.M.M. et al. Adaptação de um centro de P\&D a mudanças estruturais no seu setor de atuação: o caso do CPqD. In: SIMPÓSIO DE GESTÃO DA INOVAÇÃO TECNOLÓGICA, 22., 2002, Salvador. Anais.... São Paulo: PGT/USP, 2002. 1 CD-ROM.

HIRATUKA, C. Internacionalização de atividades de pesquisa e desenvolvimento das empresas transnacionais - análise da inserção das filiais brasileiras. São Paulo em Perspectiva, São Paulo, v. 19, n. 1, p. 105-114, jan./mar. 2005.

KUEMMERLE, W. Building effective R\&D capabilities abroad. Harvard Business Review, Boston, v. 75, n. 2, p. 61-70, 1997. 
Eva Stal \& Milton de Abreu Campanário

KUMAR, N. Determinants of location of overseas R\&D activity of multinational enterprises: the case of US and Japanese corporations. Research Policy, Amsterdam, v. 30, n. 1, p. 159174, Jan. 2001.

MARTINS, G. A. Estudo de caso - uma estratégia de pesquisa. São Paulo: Atlas, 2006.

MATESCO, V. R. Comportamento tecnológico das empresas transnacionais em operação no Brasil. São Paulo: SOBEET, 2000.

MINISTÉRIO DA CIÊNCIA E TECNOLOGIA. Secretaria de Política de Informática. Relatório de atividades 2007. Disponível em <www.mct.gov.br/sepin>. Acesso em: 20 mar. 2008.

NARULA, R.; ZANFEI, A. Globalization of innovation: the role of multinational enterprises. In: FAGERBERG, J.; MOWERY, D. C.; NELSON, R. R. (Eds.). The Oxford Handbook of Innovation. Oxford: Oxford University Press, 2005. P. 318-344.

OLIVEIRA JUNIOR, M. M.; BORINI, F. M. Subsidiárias de empresas multinacionais: estratégia, inovação e criação de valor. In: TANURE, B.; DUARTE, R. G. (Orgs.). Gestão internacional. São Paulo: Saraiva, 2006. P. 81-106.

ORGANISATION FOR ECONOMIC CO-OPERATION AND DEVELOPMENT. Science, Technology and Industry Outlook 2006. Paris: OECD, 2006.

PATIBANDLA, M.; PETERSEN, B. Role of transnational corporations in the evolution of a high-tech industry: the case of India's software industry. World Development, Kidlington, v. 30, n. 9, p. 1561-1577, 2002.

PERINI, F. Redes de conhecimento no Brasil: uma análise organizacional da Lei de Tecnologia da Informação e Comunicação (TIC). Parcerias Estratégicas, Brasília, n. 25, p. 7- 46, dez. 2007.

RITZ, R. Institutos privados de P\&D no Brasil: uma análise do setor de tecnologias de informação e comunicação. 2008. 264f. Tese (Doutorado em Política Científica e Tecnológica) - Instituto de Geociências, Universidade Estadual de Campinas, Campinas.

RUGMAN, A. M. Inside the multinationals: the economics of internal markets. New York: Columbia University Press, 1981.

SOCIEDADE BRASILEIRA DE ESTUDOS DE EMPRESAS TRANSNACIONAIS E DA GLOBALIZAÇÃO ECONÔMICA. Investimentos diretos estrangeiros e atividades de P\&D: perspectivas para o Brasil. Boletim da SOBEET, São Paulo, v. 3, n. 36, p. 1-2, ago. 2005.

STAL, E. Empresas transnacionais no Brasil e a descentralização das atividades de pesquisa e desenvolvimento. In: SIMPÓSIO DE GESTÃO DA INOVAÇÃO TECNOLÓGICA, 22., 2002, Salvador. Anais.... São Paulo: PGT/USP, 2002. 1 CD-ROM.

STAL, E.; CAMPANARIO, M. A. Países em desenvolvimento e a atração de centros de pesquisa e desenvolvimento de empresas multinacionais. In: FLEURY, A.; FLEURY, M. T. L. (orgs.). Internacionalização e os países emergentes. São Paulo: Atlas, 2007. p. 267-283.

UNITED NATIONS CONFERENCE ON TRADE AND DEVELOPMENT. Globalization of R\&D and developing countries. New York: United Nations, 2005a.

UNITED NATIONS CONFERENCE ON TRADE AND DEVELOPMENT. World Investment Report 2005 -Transnational Corporations and the Internationalization of R\&D. New York: United Nations, 2005b. 
Inovação em subsidiárias de empresas multinacionais: a aplicação do paradigma eclético de dunning em países emergentes

UNITED NATIONS CONFERENCE ON TRADE AND DEVELOPMENT. World Investment Report 2010 - Investing in a Low-Carbon Economy. New York: United Nations, 2010

YIN, R. K. Estudo de caso: planejamento e métodos. 3. ed. Porto Alegre: Bookman, 2005.

ZANATTA, M.; QUEIROZ, S. The role of national policies on the attraction and promotion of MNE's R\&D activities in developing countries. International Review of Applied Economics, Abingdon, v. 21, n. 3, p. 419-435, July 2007.

\title{
RESUMO
}

Este artigo tem como objetivo mostrar como políticas públicas constituem um componente extremamente relevante para aumentar a atratividade dos países emergentes, influenciando diretamente as variáveis do paradigma eclético de Dunning, uma das principais teorias que explicam o processo de internacionalização de empresas. As três variáveis que constituem o modelo - propriedade, localização e internalização - determinam a viabilidade de uma empresa se instalar em outro país para explorar uma vantagem competitiva, frente à alternativa de repassar este ativo a uma empresa local, por meio de uma licença, ou mediante a exportação de produtos. A análise da Lei de Informática, criada em 1991 para estimular a produção de equipamentos de informática e telecomunicações no país, mostrou que ela foi fundamental para a atração de grandes empresas multinacionais. Os resultados demonstram que a exigência de realização de atividades de $\mathrm{P} \& \mathrm{D}$ levou à criação de institutos privados de pesquisa, responsáveis em grande parte pela disseminação de conhecimento e pela capacitação tecnológica local, especialmente no polo de alta tecnologia de Campinas. Como metodologia, foi utilizada a abordagem qualitativa e o método do estudo de caso múltiplo, com a realização de entrevistas em três empresas e quatro institutos de pesquisa. Conclui-se que o governo tem um papel essencial na definição de instrumentos que aumentem a atratividade do país para a realização de atividades de inovação pelas empresas multinacionais, aumentando sua competitividade frente a subsidiárias em outros países.

Palavras-chave: paradigma eclético; empresas multinacionais; inovação tecnológica; Lei de Informática; incentivos fiscais.

\section{INNOVATION IN SUBSIDIARIES OF MULTINATIONAL COMPANIES: THE APPLICABILITY OF DUNNING'S ECLECTIC PARADIGM IN DEVELOPING COUNTRIES}

\begin{abstract}
The objective of this paper is to show how public policies are extremely relevant means of enhancing the attractiveness of emerging countries, through their influence over the variables of Dunning's Eclectic Paradigm, one of the main theories that explain the internationalization process of firms. The three variables that make up the model - ownership, location and internalization - determine the feasibility of a company establishing a subsidiary in another country to explore a competitive advantage, compared to the alternative of transferring this asset to a local firm, by means of a license, or through product exports. Through the analysis of the Informatics Act, launched in 1991 to stimulate the local production of informatics and telecommunication equipment, we conclude that it was essential to attract big multinational companies. The methodology included a qualitative approach and the multiple study case
\end{abstract}


method, with semi-structured interviews in three companies and four institutes. The results show that the requirement for doing R\&D activities led to the creation of private research institutes, which were in great part responsible for the dissemination of knowledge and local learning, especially in the high technology pole of Campinas. We conclude that the government has a fundamental role in defining instruments that increase the attractiveness of the country for the performance of innovation activities by multinational companies.

Keywords: eclectic paradigm; multinational companies; technological innovation; Informatics Act; tax incentives. 